\title{
Analysis of Dynamic Cournot Game in a Coopetition Supply Chain
}

\author{
Fengxia Mai, ${ }^{1,2}$ Jianxiong Zhang $\mathbb{D}^{1},{ }^{1}$ and Xiaojie Sun $\mathbb{D}^{1}$ \\ ${ }^{1}$ College of Management and Economics, Tianjin University, Tianjin 300072, China \\ ${ }^{2}$ School of Science, Tianjin University of Commerce, Tianjin 300134, China \\ Correspondence should be addressed to Xiaojie Sun; xjsun@tju.edu.cn
}

Received 30 August 2019; Revised 14 January 2020; Accepted 17 June 2020; Published 18 July 2020

Academic Editor: Youssef N. Raffoul

Copyright (C) 2020 Fengxia Mai et al. This is an open access article distributed under the Creative Commons Attribution License, which permits unrestricted use, distribution, and reproduction in any medium, provided the original work is properly cited.

In the original manufacturing industry, upstream encroachment has become a universal commercial phenomenon. This paper considers a coopetition supply chain consisting of an upstream original design manufacturer (ODM) and a downstream original equipment manufacturer (OEM) and proposes a dynamic Cournot game under bounded rationality. To cope with a dynamic repeated game in discrete time, a gradient adjustment mechanism is adopted. Furthermore, bifurcation diagram, largest Lyapunov exponent, basin of attraction, and critical curve are introduced to investigate the dynamic behavior of this game. The results obtained show that as the firms' policy adjustment speeds increase, the stability region of the dynamic system gradually narrows, but one special finding is that the complex behavior of the dynamic system is alleviated as the OEM's adjustment speed greatly increases. Moreover, when the difference between the two firms' adjustment speeds is relatively small, the dynamic adjustment strategy is beneficial to the coopetition supply chain and both firms under certain adjustment speeds, as compared to a one-shot game. In addition, a higher product substitutability has a positive impact on the system stability, pushing the "cooperation" business alliance towards a more coordinated outcome.

\section{Introduction}

With the development of economy and society, it is common that original design manufacturers (ODMs), such as Flextronics, Quanta, and Compal, offer design, manufacturing, and other services to original equipment manufacturers (OEMs) [1]. To expand market share and improve profit, some upstream ODMs develop own brands and directly sell their products to consumers, competing with downstream OEMs in the consumer market. Recently, facilitated by advanced e-commerce, upstream encroachment has become a feasible and universal commercial phenomenon in the original manufacturing industry. For instance, Samsung reportedly supplied billion of parts for Apple, including high-quality touch screen displays for mobile devices. Meanwhile, Samsung developed the Galaxy Tab product line, which was arguably a major competitor to Apple's iPad in the mobile device end-market [2]. Not only in consuming electronics industry but also in fashion industry, upstream firms are getting more likely to launch own-brand products and thus become downstream firms' challengers. Clothing companies such as Ralph Lauren, the Armani Group, Hugo Boss, and Bravado have also developed exclusive lines for department stores or their own stores [3].

Ray Noorda (former CEO of Novell) first proposed "coopetition" to describe the simultaneous pursuit of cooperation and competition by companies, and later this term it was widely quoted by management scholars and managers (e.g., [4-7]). In coopetition supply chains, firms simultaneously compete and cooperate in order to maximize their profits [8]. The simultaneity of cooperation and competition arises driven by the fact that firms have both private goals and common goals when they deal with businesses such as suppliers and buyers [9]. As manufacturer encroachment becomes more popular in recent years, its pros and cons have attracted significant academic interest. Arya and Mittendorf [10] considered a scenario in which the manufacturer encroaches on the retail market by opening a direct selling channel and showed that encroachment can lead to a win-win outcome. Bengtsson and Raza-Ullah [11] discussed the theoretical rooting of present research on coopetition and pointed to the need for an integration of theories on 
competition dynamics and cooperative interactions in social networks. Moreover, they argued that the future growth of the coopetition research field will hinge on creatively combining existing theoretical approaches with novel research methods and contexts. Bligiardi et al. [6] analyzed a successful case of coopetition in the context of Italian space and defense industries and carried out a study-based research. As suggested by Bligiardi et al. [6], firms should take cooperative action when stability and balance in profit sharing reach a certain degree, and thus it was proved to be difficult in long-term maintaining this action for companies aimed at maximizing their profits. Devece et al. [12] presented a literature review and research patterns of coopetition. In this paper, we consider the nature of coopetition between two firms: The ODM involves in designing and manufacturing business, commits a uniform-wholesale price contract to the OEM, and also produces self-brand products and sales them in the downstream consumer market; both the ODM and the OEM can observe the final demand potential and simultaneously make the quantities decision to develop the market for their products.

In a set of papers (e.g., [10,13-15]) on coopetition supply chain, the problem of supply contract production was considered as a one-shot interactive process between two firms with perfect rationality. These research studies directly analyzed decision results of competitive OEMs and ODMs in Nash equilibrium. Nevertheless, when firms cannot obtain the complete market information, that is, the case of bounded rationality, they always need to adjust the production quantities and play a dynamic repeated game in the long-term production process. Motivated by Bengtsson et al. [16] and Bligiardi et al. [6], we consider such dynamic competition and cooperation in practice and investigate the stability of a dynamic adjustment process. Our work extends the existing literature on one-shot game (e.g., $[10,14])$ to a case of the dynamic repeated game in a long-term production process by explicitly modelling the firms' bounded rationality.

There are some references on the complex dynamic system applied in supply chain management to analyze firms' interaction and competition. In particular, the oligopoly game between two players with bounded rationality has received considerable attention from researchers. Yang et al. [17] built up a new dynamic Cournot duopoly game model between two team players in exploitation of a renewable resource. Askar [18] analyzed the complex dynamics of a Cournot duopoly game by constructing nonlinear demand function. Shi et al. [19] analyzed the stability of the Nash equilibrium arising in the game between an OEM and a remanufacturer and showed that a higher willingness-to-pay (WTP) of consumers can either strengthen or weaken the stability of the Nash equilibrium. Ma and Xie [20] developed the dynamic game models for two scenarios in which the manufacturer, respectively, holds symmetric and asymmetric channel power to the retailer in a dual-channel supply chain. They demonstrated that the manufacturer's profit is higher with asymmetric channel power than with symmetric channel power. Villena and Araneda [21] explored the stability and chaos of a retail competition and concluded that retail multistore competition is less stable than traditional small business. Yuan and Hwarng [22] investigated the demand dynamics, under a demandbased pricing policy, of a frequently purchased service with considerations of social interaction and customers' adaptively forward-looking behavior. Some studies (e.g., $[7,23,24])$ examined the impact of nonlinear cost on dynamic Cournot oligopoly game under boundedly rational expectation. Overall, the players' interaction and competition play a significant role in a supply chain.

More recently, some researchers have begun to use dynamic game method to study realistic management questions, such as service value, channel conflict, social influence, and spillover effect. Zhang and Wang [25] examined two dynamic pricing strategies in a dualchannel supply chain with considering service value and focused on the effect of service value on decisions and an insight into complexity. Guo [26] investigated the channel conflict represented by a dynamic competition between online retailers and traditional retailers and discussed the impact of online customer reviews in a dual-channel supply chain from a dynamic perspective. Bischi et al. [27] studied the evolutionary dynamics in club goods binary games with social influence. Zhou et al. [28] established a dynamic two-stage Cournot duopoly game with R\&D spillover effect and product differentiation. Zhou and Wang [29] also studied a duopoly game with considering R\&D spillover and price competition. These papers discussed the stability and dynamics of evolutionary games and provided some methods and perspectives for analyzing complex characteristics in practical management.

In this paper, we focus on studying the dynamics and the interaction of competition and cooperation in the original manufacturing industry and make use of the advanced tool of complex system theory to extend the analysis of coopetition relationship by addressing the following research questions: (i) What are the conditions under which the OEM and the ODM can maintain their long-term coopetition relationship in a dynamic repeated game? In other words, what are the effects of key system parameters on the stability of the dynamic game? (ii) What is the dynamic behavior of this system? (iii) How do initial variables affect the efficiency of the coopetition supply chain?

To address these questions, we consider a two-echelon coopetition supply chain, where an upstream ODM and a downstream OEM play a dynamic Cournot game in the consumer market and propose a dynamic repeated game model under bounded rationality. To the best of our knowledge, the paper is the first to consider the duopoly repeated game in a coopetition supply chain with consideration of bounded rationality by using analytical and numerical tools. In particular, we adopt a gradient adjustment mechanism in economics literature to capture players' bounded rationality [30]. As reported in Cavalli and Naimzada [31] and Askar [18], a common feature in the existing literature is that "when the speed of adjustment increases, the Nash equilibrium becomes unstable." 
Different from the destabilizing role of an increase in adjustment speed, we find that the increase can reduce the complex behavior of this system, changing from a chaotic state to a two-periodic cycle.

As is well known, Cournot model is the earliest duopoly quantity game, in which two firms compete in output with simpleminded expectation. Many works have paid attention to the stability and complex behavior (such as bifurcation, chaos, and strange attractors) in dynamic Cournot game models [31-36]. Through dynamic analysis of Cournot game in a coopetition supply chain, in this paper, we mainly obtain the following insights: (i) The increase of the demand substitutability has a positive impact on the system stability. This means quantity competition makes this "cooperation" business alliance reach a more coordinated outcome. (ii) As adjustment speeds increase, the Nash equilibrium becomes unstable. This is consistent with the facts drawn from the previous literature $[19,20,31,35]$. However, our results show that the complex behavior of the dynamic system is alleviated from chaos to a two-periodic cycle along with the OEM's adjustment speed greatly increasing. (iii) For global stability, the system can eventually maintain the stability in a large region of initial variables. This also means that the firms can set the initial variables in a large adjustment range to make the system converge to the equilibrium. (iv) By comparing the influences of the adjustment speeds on the firms' average profits in the dynamic system with that in the one-shot game, we find that the dynamic adjustment strategy is beneficial to the coopetition supply chain and both players when the difference between the firms' adjustment speeds is relatively small.

The remainder of this paper is organized as follows. We describe the problem and model the dynamic system in Section 2. In Section 3, we present the conditions under which the Nash equilibrium is locally stable. In Section 4, numerical simulations are devoted to the investigation of the local bifurcations and the dynamic trajectories. The global dynamics of the system are analyzed in Section 5. Profit comparison between the dynamic repeated game and the one-shot game is presented in Section 6. Finally, Section 7 concludes this study.

\section{Model Description}

Consider a supply chain consisting of an OEM (referred to as "he," labeled by $e$ ) and an ODM (referred to as "she," labeled by $d$ ) in which the OEM outsources his production to the ODM, and the ODM meanwhile produces her own-brand products. As a result, the ODM inevitably competes with her downstream OEM in the retail market through a Cournot duopoly model. In other words, the ODM is not only a downstream competitor of the OEM in customer market but also an upstream business partner. To characterize the relationship between product price $p$ and production quantity $q$, the inverse demand function is defined as

$$
p_{i}\left(q_{i}, q_{j}\right)=\alpha-q_{i}-\gamma q_{j}, \quad i, j=e, d ; i \neq j,
$$

where $\alpha$ is the total market potential and $\gamma \in(0,1)$ denotes the substitutability of the two products (or the influence of one party's demand on the price of the other party). Note that the larger the coefficient $\gamma$, the stronger the product substitutability, which conforms to common knowledge in practice. Price $p_{i}$ is a linear function of both production quantities $q_{i}$ and $q_{j}$, and this form of linear demand has been used in the marketing and economics literature previously to deal with differentiated duopoly questions (e.g., [37-39]). In addition, $c_{e}>0$ and $c_{d}>0$ denote the unit production costs of the OEM and the ODM, respectively.

The wholesale price $w$ is considered as an exogenous variable. In general, the OEM and the ODM jointly set a wholesale price, and the ODM does not adjust the wholesale price in a repeated game once a wholesale price commitment is reached. This is because the ODM has an incentive to commit a stable wholesale price in order to maintain a longterm cooperation with the OEM. This can be driven by two reasons. First, ODMs are often involved in intense price wars, and their profit margins leave little space to adjust prices [40]. Second, the fixed wholesale price can be regarded as a strategy of price protection, which is a practice commonly used between manufacturers and retailers in the manufacturing industry, such as personal computer industry, motivated by the fact that the value of the product drops gradually during the product life cycle [41]. For example, Compaq (the first company to legally reverse-engineer the IBM Personal Computer) offered full price protection to its distributors since the fall of 1993 [42]. Apple announced in late 1993 that it was limiting price protection period to its dealers to 30 days [41]. Besides, an exogenous wholesale price allows us to focus on analyzing the interaction between quantity strategies of both firms in isolation. The problem of production strategy under price commitment has been explored in some researches (e.g., [43-45]). In this paper, once the wholesale price commitment is reached via bargaining, the ODM and the OEM compete in production quantity by estimating their respective profits given by

$$
\left\{\begin{array}{l}
\max _{q_{d}} \prod_{d}=\left(p_{d}\left(q_{d}, q_{e}\right)-c_{d}\right) q_{d}+\left(w-c_{e}\right) q_{e} \\
\max _{q_{e}} \prod_{e}=\left(p_{e}\left(q_{e}, q_{d}\right)-w\right) q_{e} .
\end{array}\right.
$$

First, we consider that the two firms are fully rational, which means that both firms simultaneously make the optimal production decisions to maximize profits. In this case, the system can reach a Nash equilibrium via a one-shot game and hence does not need a dynamic adjustment process [46]. By taking the first derivatives of the profit functions in equation (2) with respect to production quantities $q_{d}$ and $q_{e}$, respectively, we can obtain

$$
\begin{aligned}
& \frac{\partial \Pi_{d}}{\partial q_{d}}=\alpha-c_{d}-2 q_{d}-\gamma q_{e}, \\
& \frac{\partial \Pi_{e}}{\partial q_{e}}=\alpha-w-2 q_{e}-\gamma q_{d},
\end{aligned}
$$


which yield the equilibrium quantities, respectively, given by

$$
\begin{gathered}
q_{d}=\frac{2\left(\alpha-c_{d}\right)-\gamma(\alpha-w)}{4-\gamma^{2}}, \\
q_{e}=\frac{2(\alpha-w)-\gamma\left(\alpha-c_{d}\right)}{4-\gamma^{2}} .
\end{gathered}
$$

Unlike the case of full rationality in which the firms can predict perfectly the market information, in practice, the firms are often deviating from perfect consistency or rationality. To cope with this situation, a dynamic repeated game model under bounded rationality is proposed. In this game, the firms update their production strategies by using local estimate of marginal profits in discrete time periods. With such local adjustment mechanism, the firms do not have to have complete knowledge of demand and cost [47], and they only need to know how the market will respond to small production changes to adjust their production plans.

We now consider the myopic adjustment mechanism (see $[17,26,29,31])$ :

$$
q_{i}(t+1)=q_{i}(t)+\beta_{i} q_{i}(t) \frac{\partial \Pi_{i}}{\partial q_{i}}, \quad i=d, e,
$$

where $\partial \Pi_{i} / \partial q_{i}$ is the firm i's marginal profit and $\beta_{i}$ denotes the firm $i$ 's quantity adjustment speed with respect to the marginal profit $\partial \Pi_{i} / \partial q_{i}$. In other words, each firm increases or decreases the output of the next period $t+1$ on the basis of the expected marginal profit $\partial \Pi_{i} / \partial q_{i}$ of the current period $t$. Therefore, the dynamic repeated game under bounded rationality can be characterized by the following system:

$$
T\left(q_{d}, q_{e}\right):\left\{\begin{array}{l}
q_{d}(t+1)=q_{d}(t)+\beta_{d} q_{d}(t) \\
\left(\alpha-c_{d}-2 q_{d}(t-1)-\gamma q_{e}(t)\right), \\
q_{e}(t+1)=q_{e}(t)+\beta_{e} q_{e}(t) \\
\left(\alpha-w-2 q_{e}(t-1)-\gamma q_{d}(t)\right) .
\end{array}\right.
$$

Based on the above model, in the following sections, we will analyze the dynamics and the complexity of this system by using analytical and numerical methods, respectively. We will also compare the firms' profits in the dynamic repeated game with that in the case of full rationality (or the one-shot game) to obtain some managerial insights.

\section{Equilibrium Points and Local Stability}

To further investigate the effects of key parameters on the game results and profits of both firms in the decision process, in this section, we present a comprehensive numerical analysis of the dynamic system. We define the equilibrium points of the dynamic game as nonnegative fixed points of system (6). Let $q_{i}(t+1)=q_{i}(t)$, and it is easy to check that system (6) has the following equilibrium points: $E^{*}=\left(q_{e}^{*} q_{d}^{*}\right)=\left(2\left(\alpha-c_{d}\right)-\gamma(\alpha-w) / 4-\gamma^{2}, 2(\alpha-\right.$ $\left.w)-\gamma\left(\alpha-c_{d}\right) / 4-\gamma^{2}\right), E_{0}=(0,0), E_{1}=(\alpha-w / 2,0)$, and $E_{2}=\left(0, \alpha-c_{e} / 2\right)$. Equilibria $E_{0}, E_{1}$, and $E_{2}$ are called boundary equilibrium points, and $E^{*}$ is the unique interior equilibrium of system (6). To explore the local stability of the fixed point $E^{*}$, we introduce the Jacobian matrix of the mapping $T$ as follows:

$$
\begin{aligned}
& J\left(q_{d}, q_{e}\right)=\left[\begin{array}{r}
1-2 \beta_{e} q_{e}+\beta_{e}(\alpha-\gamma \\
-\beta_{d} \gamma q
\end{array}\right. \\
& \text { proposition presents the condition } \\
& \text { hen Nash equilibrium } E^{*} . \\
& \left.-\beta_{d} q_{d}^{*}\right)+\left(4-\gamma^{2}\right) \beta_{e} \beta_{d} q_{e}^{*} q_{d}^{*}>0, \\
& \left.\beta_{d} q_{d}^{*}\right)-\left(4-\gamma^{2}\right) \beta_{e} \beta_{d} q_{e}^{*} q_{d}^{*}>0,
\end{aligned}
$$

the Nash equilibrium $E^{*}$ is locally asymptotically stable.

Proof. Substituting $E^{*}=\left(q_{e}^{*}, q_{d}^{*}\right)$ into equation (7), the Jacobian matrix at $E^{*}$ can be written as

$$
J\left(E^{*}\right)=\left[\begin{array}{cc}
1-2 \beta_{e} q_{e}^{*} & -\gamma \beta_{e} q_{e}^{*} \\
-\gamma \beta_{d} q_{d}^{*} & 1-2 \beta_{d} q_{d}^{*}
\end{array}\right] .
$$

The characteristic equation of the matrix $J$ is

$$
F(\lambda)=\lambda^{2}-\operatorname{Tr}\left(J\left(E^{*}\right)\right) \lambda+\operatorname{Det}\left(J\left(E^{*}\right)\right)=0,
$$

where $\operatorname{Tr}\left(J\left(E^{*}\right)\right)$ and $\operatorname{Det}\left(J\left(E^{*}\right)\right)$ are the trace and the determinant, respectively, given by

$$
\begin{aligned}
& \left.\begin{array}{c}
\left.-\beta_{e} \gamma q_{e}\right) \\
1-2 \beta_{d} q_{d}+\beta_{d}\left(\alpha-\gamma q_{e}-w-2 q_{d}\right)
\end{array}\right] \\
& \operatorname{Tr}(J)=2\left(1-\beta_{e} q_{e}^{*}-\beta_{d} q_{d}^{*}\right), \\
& \operatorname{Det}(J)=1-2 \beta_{e} q_{e}^{*}-2 \beta_{d} q_{d}^{*}+\left(4-\gamma^{2}\right) \beta_{e} \beta_{d} q_{e}^{*} q_{d}^{*} .
\end{aligned}
$$

Since $\Delta=\operatorname{Tr}^{2}(J)-4 \operatorname{Det}(J)=\left(2 \beta_{e} q_{e}^{*}+2 \beta_{d} q_{d}^{*}\right)^{2}+4 \beta_{e}$ $\beta_{d} \gamma^{2} q_{e}^{*} q_{d}^{*}-4 \beta_{e} q_{e}^{*}$, the eigenvalues of $J\left(E^{*}\right)$ are real. According to Jury stability criterion (see $[31,35]$ ), the condition guaranteeing the locally asymptotical stability of the Nash equilibrium $E^{*}$ is that the eigenvalues of $J\left(E^{*}\right)$ are inside the unit circle. Therefore, the coefficients of characteristic polynomial meet the following conditions:

$$
\left\{\begin{array}{l}
1-\operatorname{Tr}(J)+\operatorname{Det}(J)>0 \\
1+\operatorname{Tr}(J)+\operatorname{Det}(J)>0 \\
1-\operatorname{Det}(J)>0
\end{array}\right.
$$

where the first condition $1-\operatorname{Tr}(J)+\operatorname{Det}(J)=$ $\left(4-\gamma^{2}\right) \beta_{e} \beta_{d} q_{e}^{*} q_{d}^{*}>0$ is always satisfied. The second condition can be transformed into $1+\operatorname{Tr}(J)+\operatorname{Det}(J)=4(1-$ $\left.\beta_{e} q_{e}^{*}-\beta_{d} q_{d}^{*}\right)+\left(4-\gamma^{2}\right) \beta_{e} \beta_{d} q_{e}^{*} q_{d}^{*}>0$. It is clear that the third condition $\operatorname{Det}(J)<1$ is equivalent to $2\left(\beta_{e} q_{e}^{*}+\right.$ $\left.\beta_{d} q_{d}^{*}\right)-\left(4-\gamma^{2}\right) \beta_{e} \beta_{d} q_{e}^{*} q_{d}^{*}>0$. The proof is complete. 
As presented above, the stability conditions in Proposition 1 can be obtained by solving the inequations in equation (12). However, if any of them changes from an inequality to an equality with the other two remaining unchanged, the equilibrium loses its stability through one of the three bifurcations by virtue of the dynamic system theory (see [48, 49]): when $1-\operatorname{Tr}(J)+\operatorname{Det}(J)=0$, through a transcritical bifurcation; when $1+\operatorname{Tr}(J)+\operatorname{Det}(J)=0$, through a flip bifurcation; or when $1-\operatorname{Det}(J)=0$, through a Neimark-Sacker bifurcation. Next, we set parameter values: $\alpha=1, \gamma=0.5, c_{d}=0.0625$, and $w=0.1$, and then the Nash equilibrium can be calculated as $E^{*}=(0.38,0.355)$, which is locally asymptotically stable when the conditions in equation (8) hold. The system parameter values in the simulation study can ensure the existence of the equilibrium solution under full rationality. In such a setting, the stability region of the Nash equilibrium in the parameter plane of adjustment speeds $\left(\beta_{e}, \beta_{d}\right)$ is shown in Figure 1. It can be observed that the equilibrium $E^{*}$ loses its stability through the flip bifurcation. This demonstrates that the increase in the adjustment speed $\beta_{i}$ reduces the stability of the Nash equilibrium, which is consistent with analytic results in some literature (e.g., [31, 46, 50]).

In addition, Figure 2 reports the impact of the product substitutability $\gamma$ on the system stability with $\gamma$ taking various values and other parameter values remaining constant. As the product substitutability increases, the intersection of the bifurcation curve with $\beta_{e}$-axis moves rightwards and that with $\beta_{d}$-axis moves upwards, which indicates that the size of the stability region increases with the product substitutability. This implies that a higher product substitutability has a positive impact on the local stability of the dynamic system; and, from a practical view, the quantity competition pushes the "cooperation" business alliance towards a more coordinated outcome.

\section{Analysis of Dynamics}

In this section, we introduce bifurcation diagram and largest Lyapunov exponent (LLE) to investigate the dynamics of system (6). We perform a series of numerical stimulations and sensitivity analyses of key system parameters to provide some main theoretical results and practical insights. In the following, we will present how the dynamic system evolves as the adjustment speed $\beta_{d}$ or $\beta_{e}$ changes. Other parameters will always follow the setting: $\alpha=1, \gamma=0.5, c_{d}=0.0625$, and $w=0.1$

As is known, bifurcation diagram can clearly illustrate the dynamic characteristics of a system. Figures 3(a) and 3(b), respectively, present the bifurcation diagrams of quantity strategies $q_{d}$ and $q_{e}$ with respect to the adjustment speed $\beta_{d}$ with $\beta_{e}=0.73$ and the initial conditions $q_{d}(0)=$ 0.419 and $q_{e}(0)=0.398$. They reveal the sequence of period doubling bifurcation (namely, periods $2,4,8, \ldots$ ) that leads to the instability at an equilibrium point as the adjustment speed $\beta_{d}$ increases, and the first flip bifurcation occurs through which a stable two-periodic cycle emerges at $\beta_{d}=2.681$. It can be concluded that a lower adjustment speed of the ODM makes the system more stable, and the

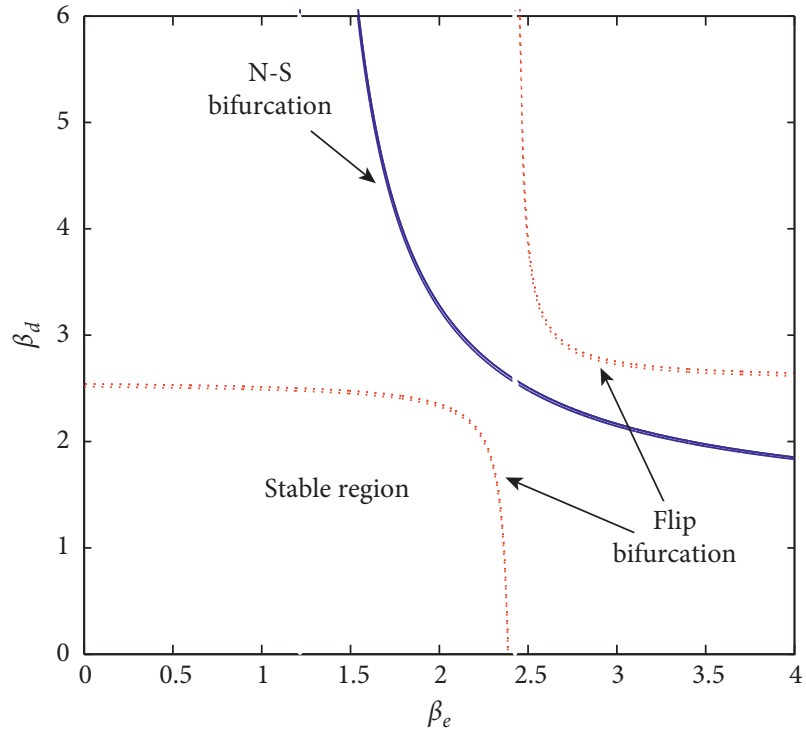

FIGURE 1: Stability region of the Nash equilibrium with respect to $\left(\beta_{e}, \beta_{d}\right)$.

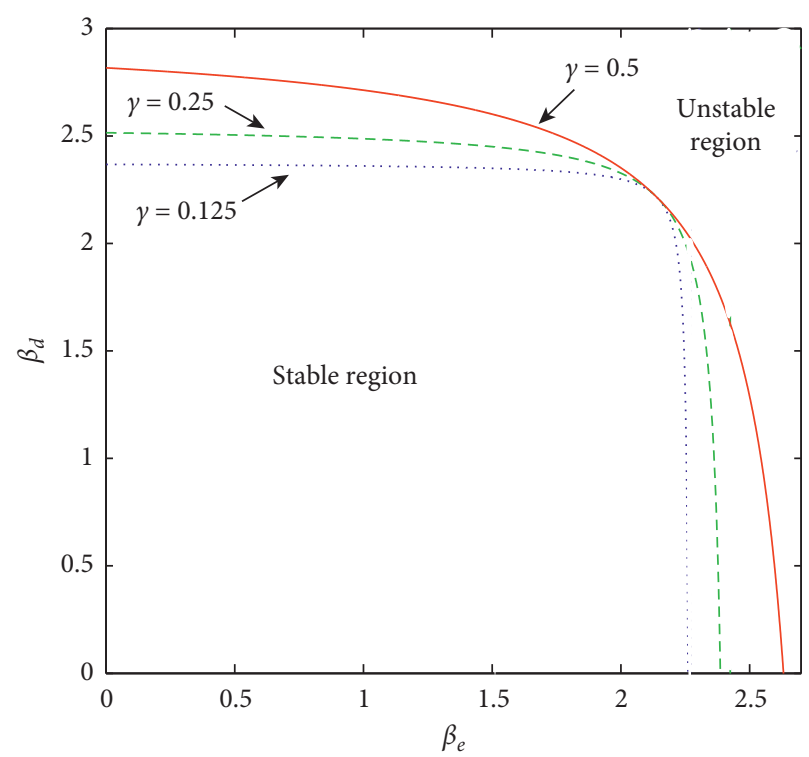

FIGURE 2: Stability region of the Nash equilibrium with respect to $\left(\beta_{e}, \beta_{d}\right)$ under different $\gamma$.

equilibrium gradually loses its stability and even reaches chaos as this adjustment speed increases. Figure 4 shows the LLE with respect to the adjustment speed $\beta_{d}$ corresponding to the bifurcation diagrams in Figure 3, where LLE is also an indicator to inspect the set of parameters that makes trajectory converge to periodic orbit, quasiperiodic, and chaotic attractor over time $[19,26]$. With the increase in $\beta_{d}$, the evolution of the system becomes more and more complex. In general, stabilization presents that the system converges to Cournot-Nash equilibrium after a few periods. However, if evolution trajectory becomes periodic, players should adjust their quantities regularly. When chaos occurs, quantities are irregular and depend on initial 


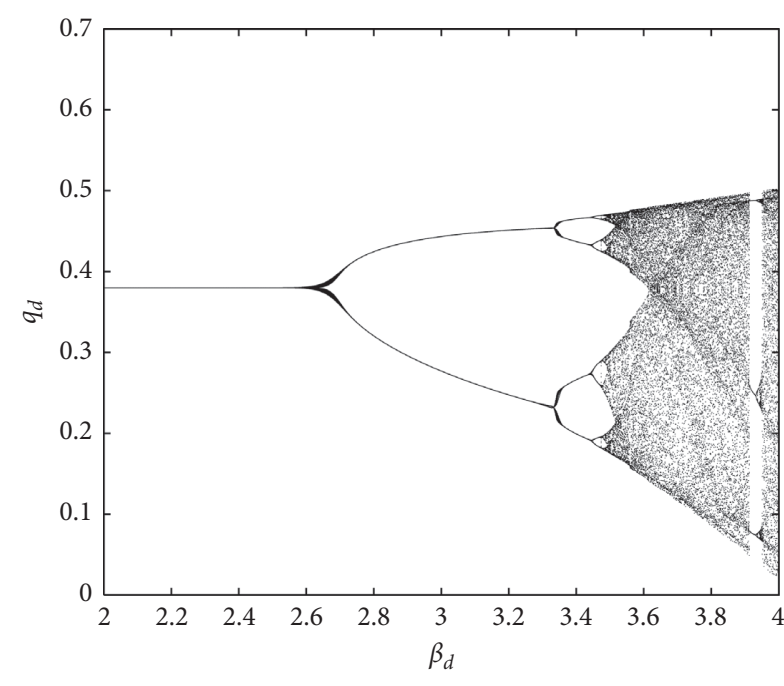

(a)

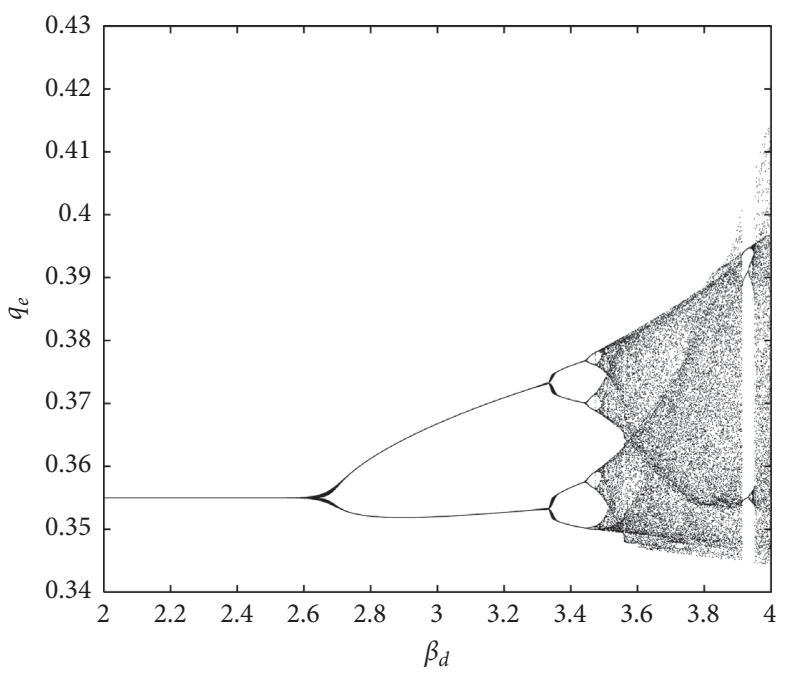

(b)

FIgURE 3: Bifurcation diagrams of $q_{d}$ and $q_{e}$ with respect to $\beta_{d}$, with $\beta_{e}=0.73$.

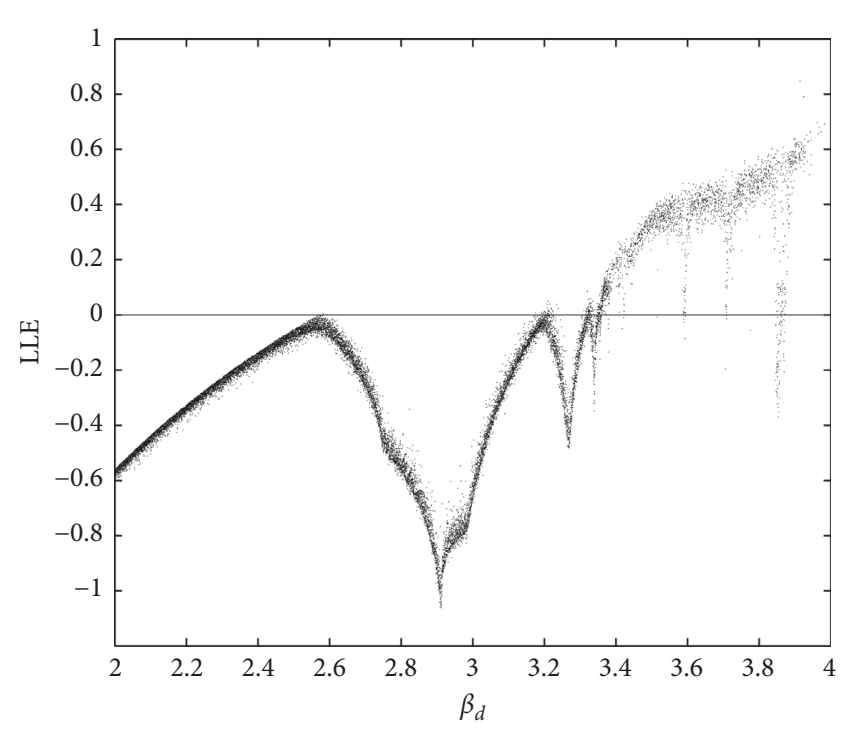

FIGURE 4: Largest Lyapunov exponent with respect to $\beta_{d}$, with $\beta_{e}=0.73$.

values sensitively. Therefore, it is difficult for firms to make long-term decision strategies in this situation. Echoing practical experience, the ODM hence should cautiously select the adjustment speed to keep the system stable and avoid dropping into a chaotic state.

Next, Figures 5 and 6 report the sensitivity analysis of the adjustment speed $\beta_{e}$ by setting different values to obtain its impacts on the dynamic system (6). As compared to the bifurcation diagrams in Figure 3, we find that, for much larger values of $\beta_{e}$, there are significant differences in evolution trajectory of the dynamic system. As observed from Figures 5 and 6 , the system is always stable in a relatively long interval of parameter $\beta_{d}$ at first and then loses its stability to result in chaos but thereafter turns into period doubling bifurcation and finally gets into a chaotic state, which is obviously different from the evolution processes presented in Figure 3. This shows that the complexity of the system is reduced, changing from chaos to two-periodic cycle, as the adjustment speed $\beta_{e}$ greatly increases. Furthermore, Figures 5 and 6 also imply that the system's intermediate chaos region before the period of two-periodic cycle is increasing with $\beta_{e}$, and the range of $\beta_{d}$ for system stability is decreasing with $\beta_{e}$, demonstrating that the Nash equilibrium becomes unstable as the OEM's adjustment speed increases.

These results show that as the firms' adjustment speeds increase, the stability region of the dynamic system gradually reduces, but one special finding is that the system changes from chaos to a two-periodic cycle when the adjustment speed of the OEM increases sharply, and thus the complex behavior of the system is alleviated.

\section{Global Analysis}

In the previous section, the scope of local analysis is confined to a small neighborhood of the equilibrium point, which may not involve the impacts of initial parameter values, due to the firms' subjective judgements for the market under bounded information at the beginning of the game. Hence, a global analysis is necessary to investigate the long-run behavior of the dynamic system, which has been discussed by some works such as Bischi and Naimzada [46], Agliari et al. [51], and Bischi et al. [27]. Figure 7 shows the attractor and its basin of attraction, where critical curves $\mathrm{LC}^{a}$ and $\mathrm{LC}^{b}$ are defined as the locus of points having two, or more, coincident rank-1 preimages.

As observed from Figure 7, the shaped region is divided into three parts by the two critical curves $\mathrm{LC}^{a}$ and $\mathrm{LC}^{b}$, where symbols $Z_{0}, Z_{2}$, and $Z_{4}$, respectively, denote no, two, and four solution regions. For example, $\left(q_{d}(t), q_{e}(t)\right)$ in region $Z_{2}$ has two preimages $\left(q_{d}(t-1), q_{e}(t-1)\right)$. Note that, to obtain the critical curve LC, we introduce curves 


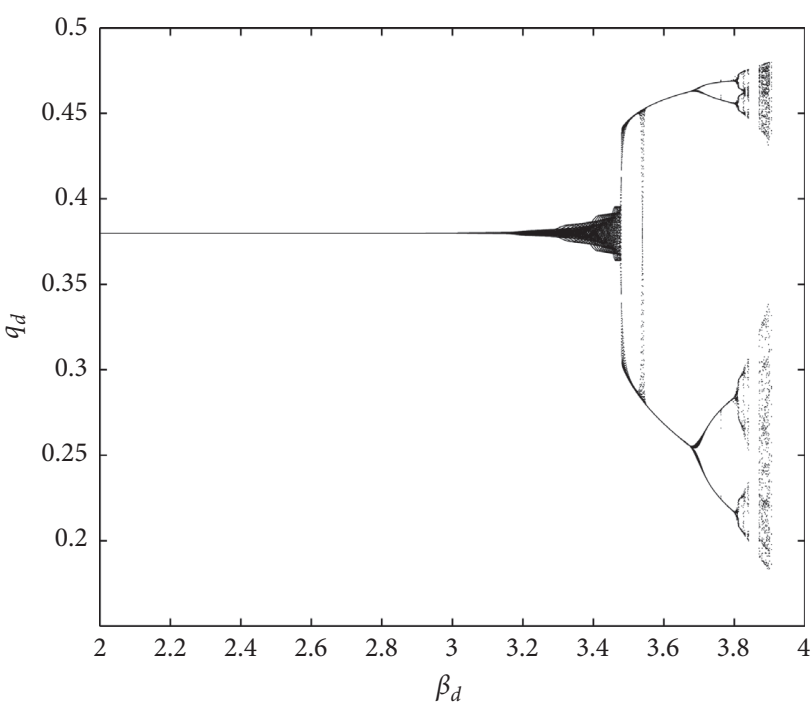

(a)

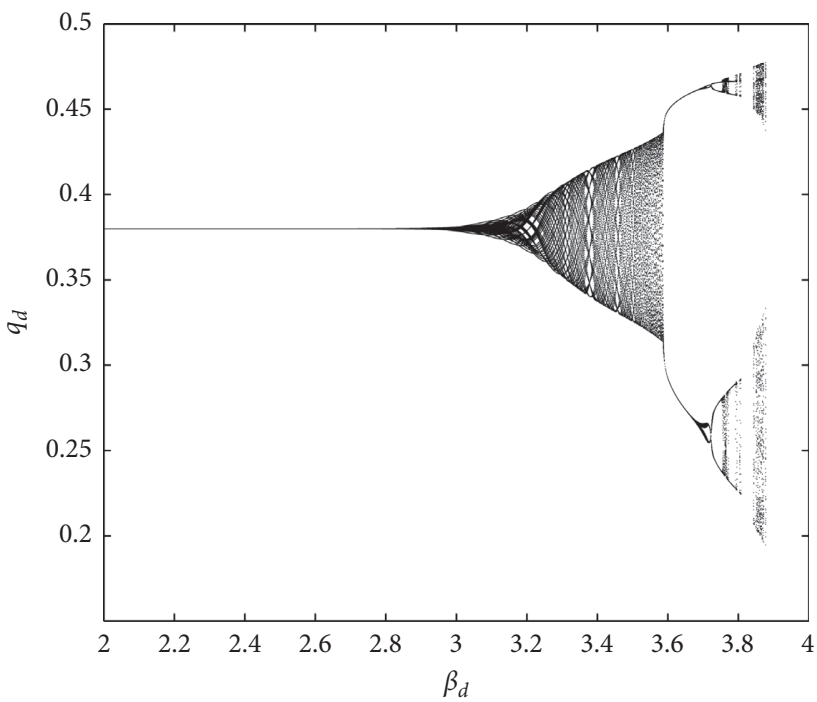

(c)

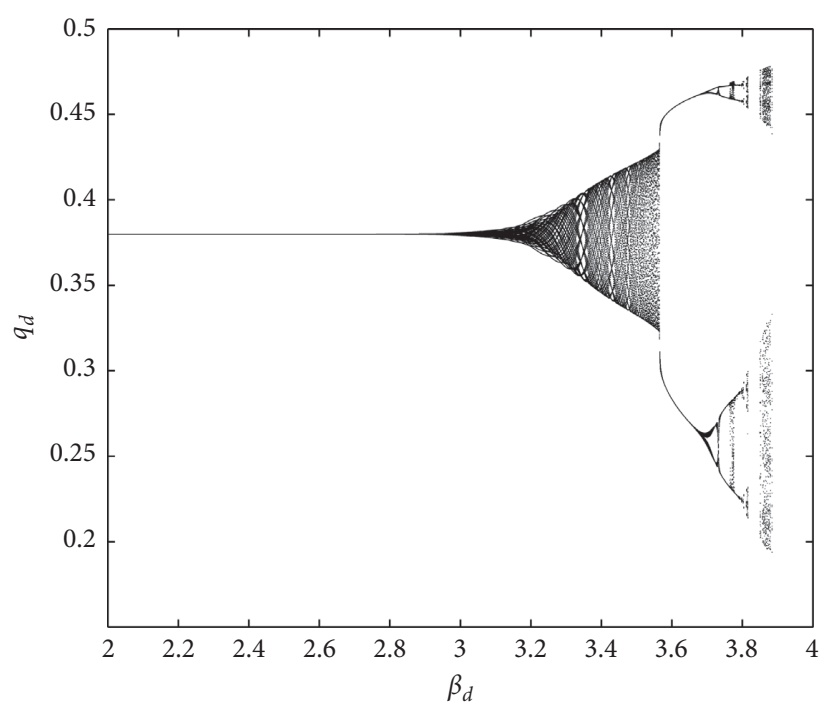

(b)

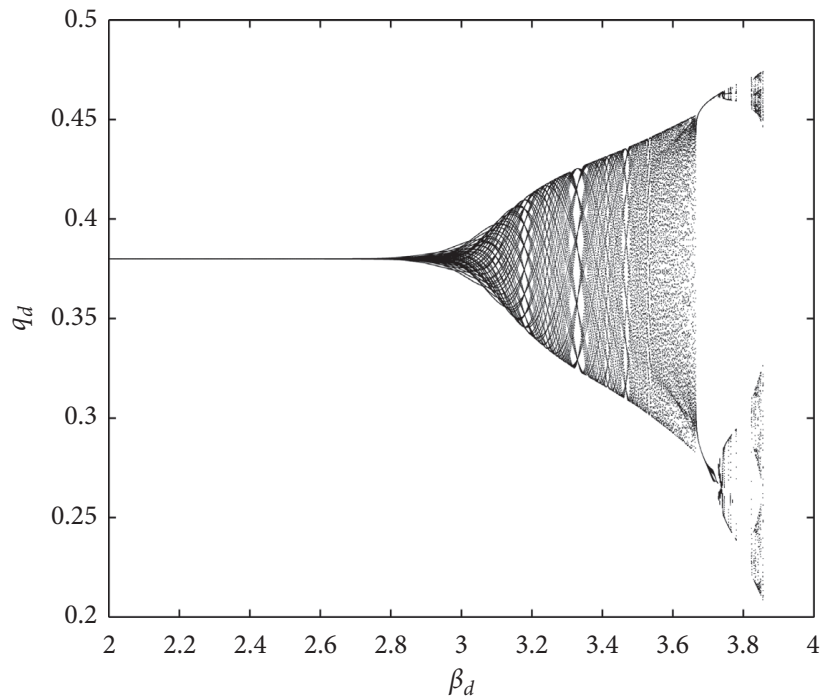

(d)

FiguRE 5: Bifurcation diagrams of $q_{d}$ with respect to $\beta_{d}$ under different $\beta_{e}$. (a) $\beta_{e}=2.265$. (b) $\beta_{e}=2.35$. (c) $\beta_{e}=2.375$. (d) $\beta_{e}=2.455$.

$\mathrm{LC}_{-1}$ as shown in Figure 7, which are the rank-1 preimages of $\mathrm{LC}$ under $T$, i.e., $T\left(\mathrm{LC}_{-1}\right)=\mathrm{LC}$, and $\mathrm{LC}_{-1}$ generally belongs to the locus of points on the condition that Jacobin determinant of $T$ vanishes; i.e.,

$$
\operatorname{LC}_{-1} \subseteq\left\{\left(q_{e}, q_{d}\right): \operatorname{Det}(J)\left(q_{e}, q_{d}\right)=0\right\} .
$$

The fixed point of the dynamic system shown in Figure 7 is $(0.3976,0.4190)$, and the yellow region is the domain of attraction in which each initial strategy can converge to the fixed point. Figure 8 presents the time series of $q_{e}$ (red dot) and $q_{d}$ (blue dot) corresponding to Figure 7, which demonstrates that the initial production quantities in the stable region converge to the equilibrium point. The results demonstrate that the firms' initial quantities have an important effect on the system stability.

\section{Profit Comparison}

The profit performances of the dynamic repeated game and the one-shot game are presented in Figure 9, where the solid curves represent the firms' profits in the repeated game and the dotted curves denote those in the one-shot game. Note that the firms' profits in the repeated game are obtained by calculating the averages of their product quantities for each adjustment speed of $\beta_{d}$.

Figure 9 shows the effects of the firms' adjustment speeds on their profits. Specifically, for different values of the OEM's adjustment speed $\beta_{e}$, the OEM's profit increases in the ODM's adjustment speed $\beta_{d}$ in the repeated game on the whole, while the ODM's profit decreases at first with a slowing rate in $\beta_{d}$ (shown in Figures $9(\mathrm{a})-9(\mathrm{c})$ ) and then 


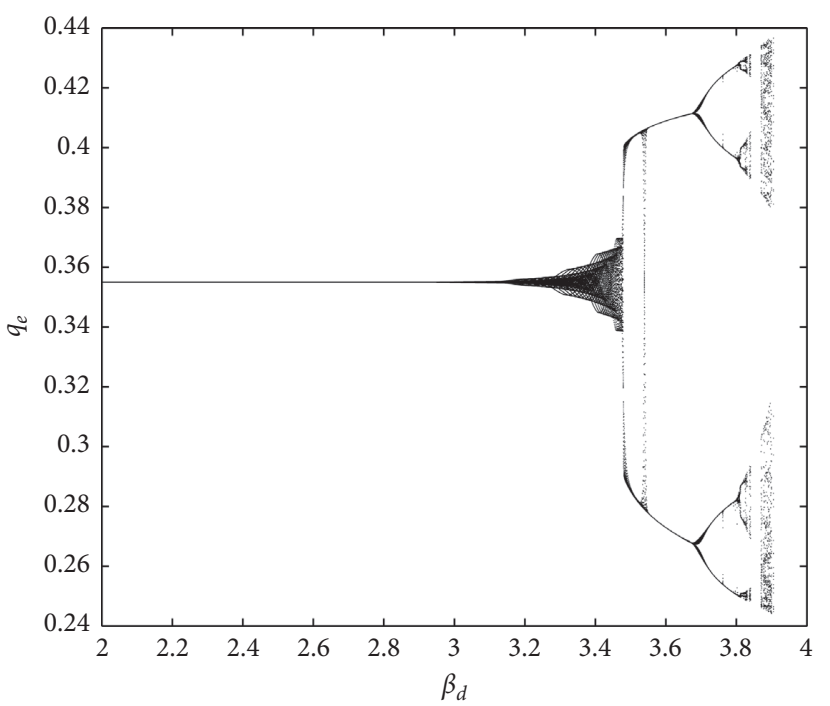

(a)

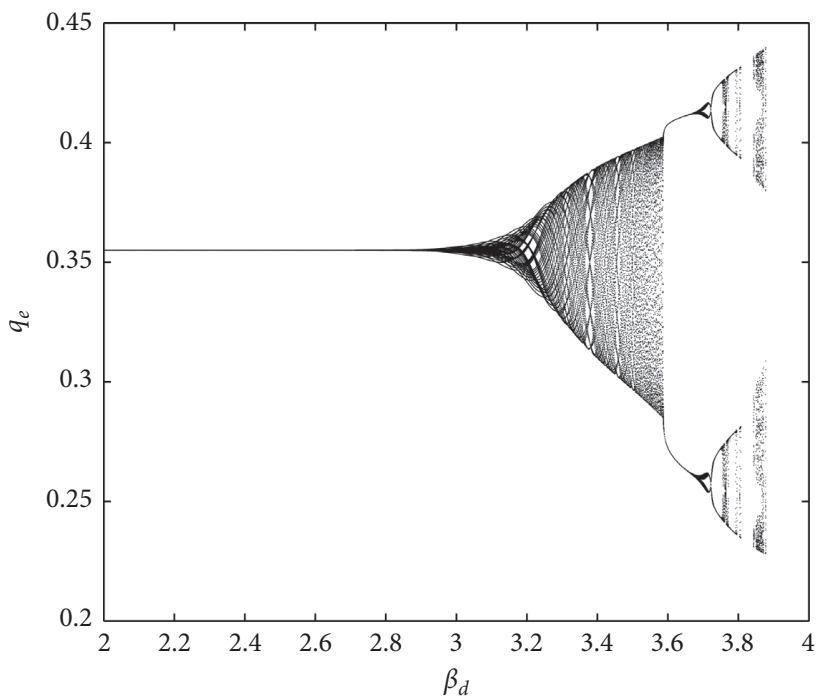

(c)

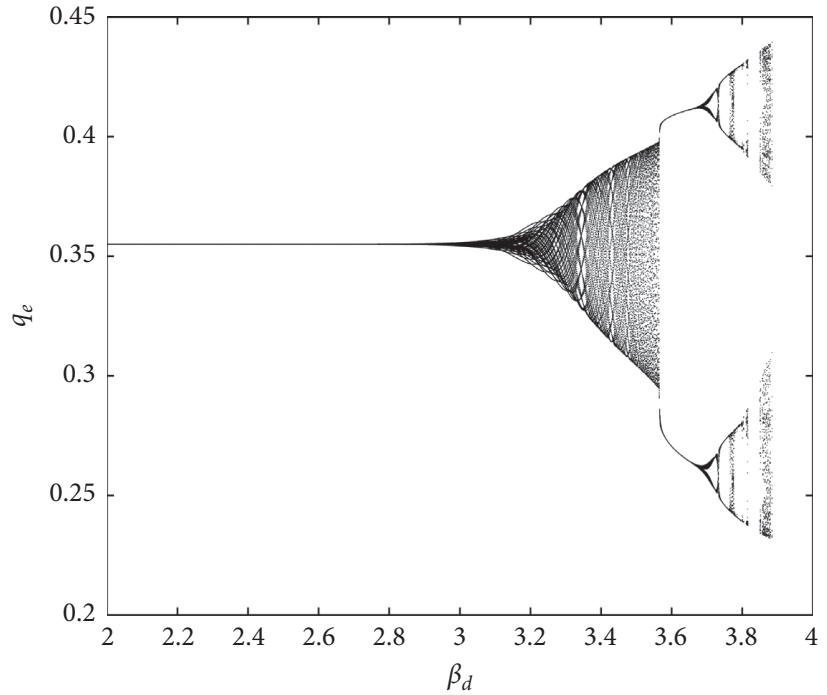

(b)

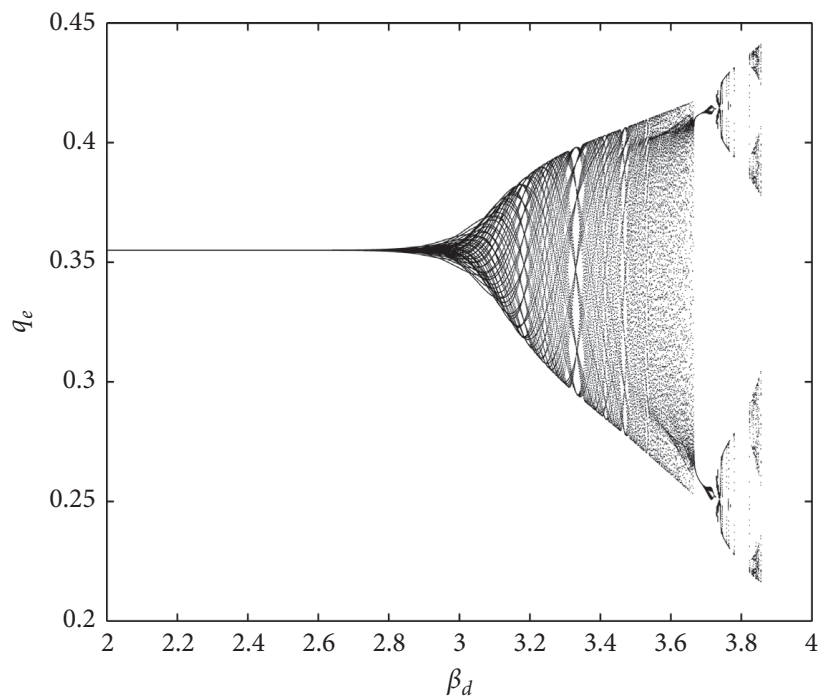

(d)

Figure 6: Bifurcation diagrams of $q_{e}$ with respect to $\beta_{d}$ under different $\beta_{e}$. (a) $\beta_{e}=2.265$. (b) $\beta_{e}=2.35$. (c) $\beta_{e}=2.375$. (d) $\beta_{e}=2.455$.

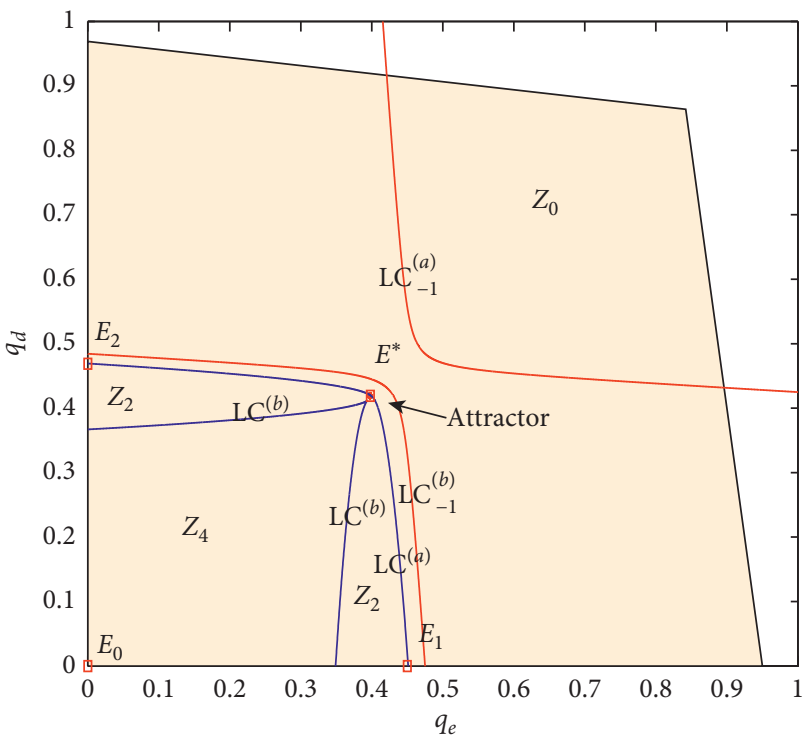

Figure 7: Attractor (red dot) and basin of attraction (yellow region), with $\beta_{e}=\beta_{d}=1$. 


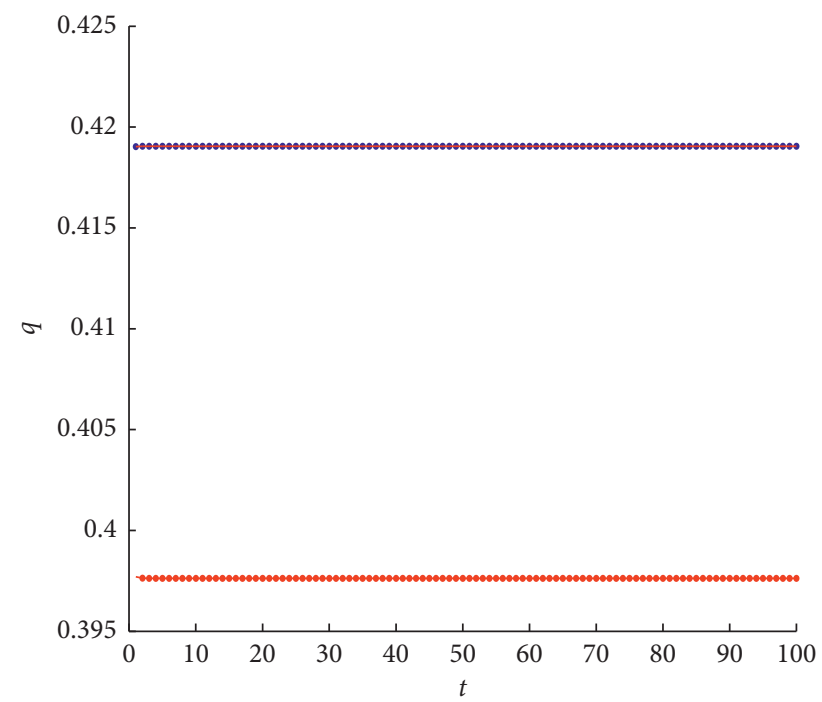

Figure 8: Time series of $q_{e}$ (red dot) and $q_{d}$ (blue dot) corresponding to Figure 7.

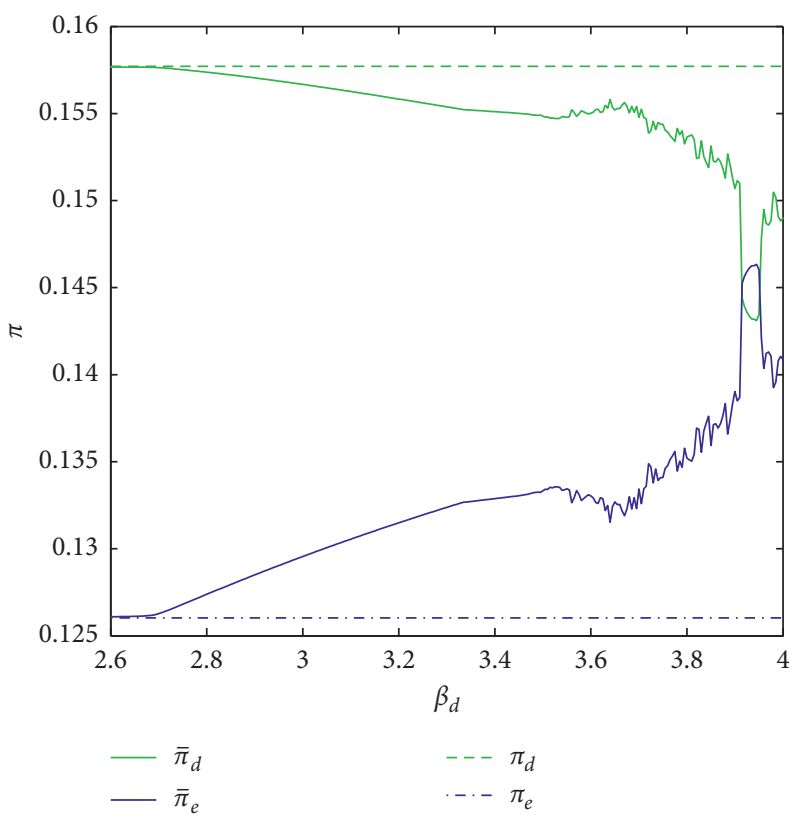

(a)

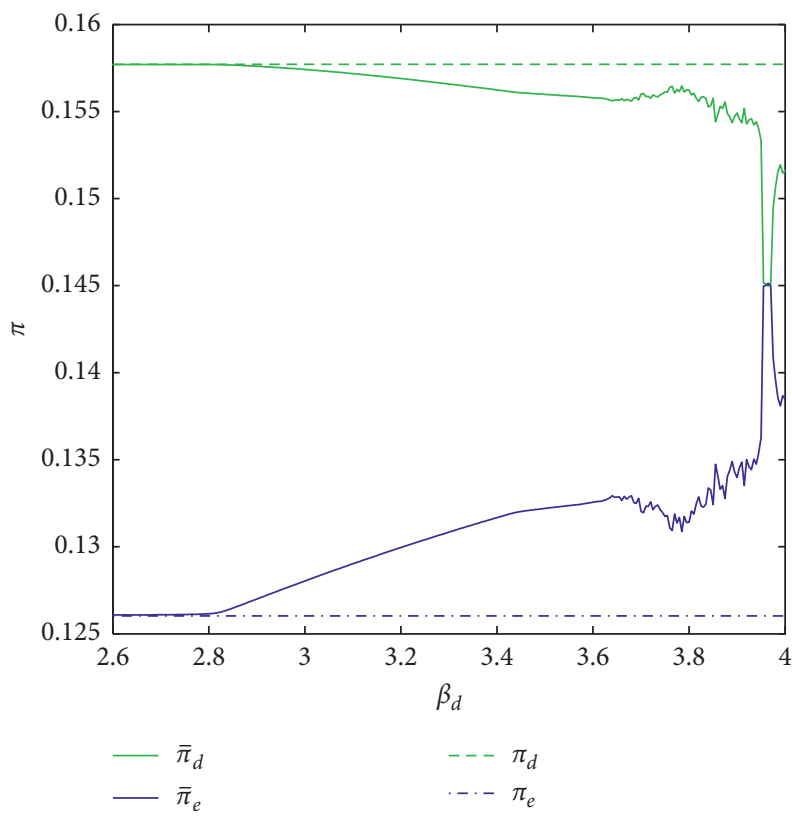

(b)

Figure 9: Continued. 


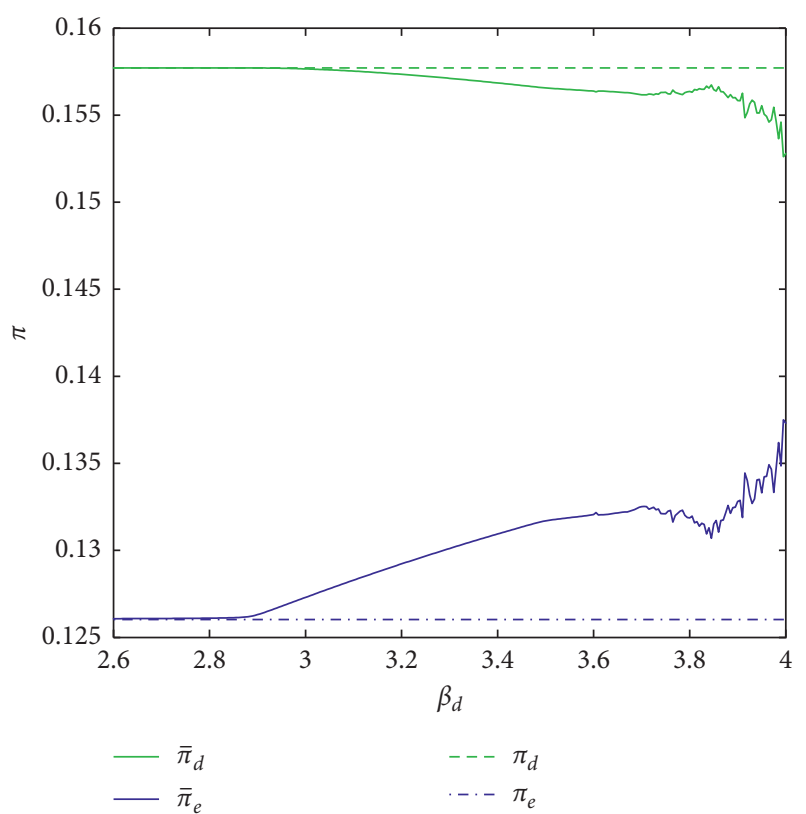

(c)

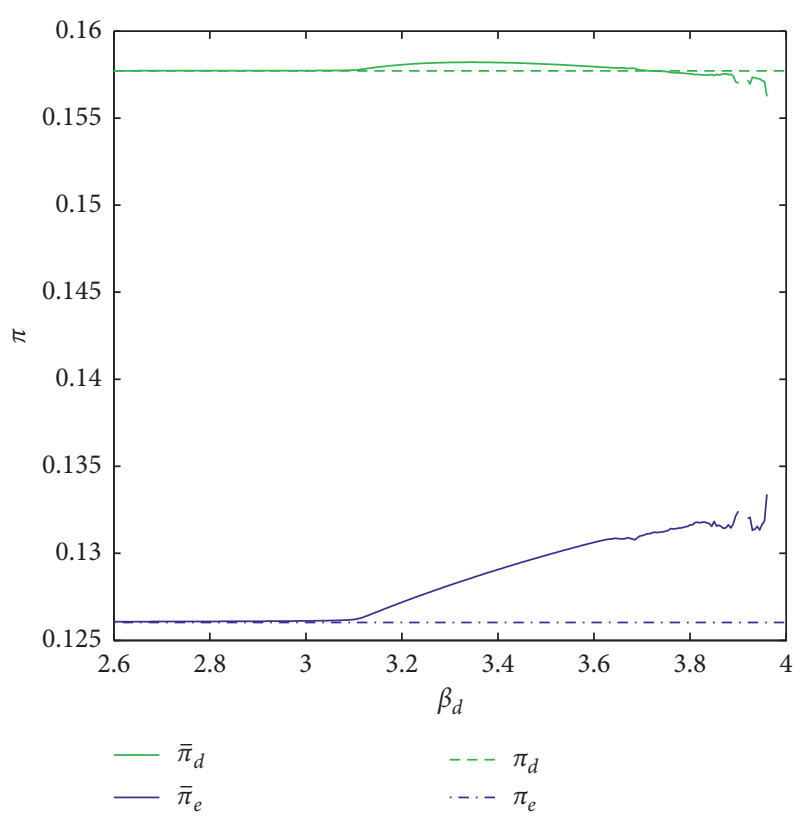

(d)

FiguRE 9: Impacts of $\beta_{d}$ and $\beta_{e}$ on the firms' profits. (a) $\beta_{e}=0.73$. (b) $\beta_{e}=1.45$. (c) $\beta_{e}=1.65$. (d) $\beta_{e}=2.265$.

increases in a certain interval of $\beta_{d}$ (shown in Figure 9(d)). This demonstrates that the increase in the ODM's adjustment speed is beneficial to the OEM but harmful to the ODM. On the contrary, the increase in the OEM's adjustment speed slows down the increase in his profit and thus damages his own interests but reduces the decline and even provides an improvement in the ODM's profit and hence benefits the ODM.

It can also be observed from Figure 9 that, as compared to the outcomes under the equilibrium strategy in the oneshot game, the OEM's profit in the repeated game is always higher (shown in Figures 9(a)-9(d)), and the ODM's profit is lower (shown in Figures 9(a)-9(c)) but becomes slightly higher in a certain interval of $\beta_{d}$ (shown in Figures 9(d)). This implies that bounded rationality can mitigate the competition between the two firms. Specifically, a win-win outcome occurs in a certain interval of $\beta_{d}$ as presented in Figures 9(d), where both firms' profits in the dynamic game are higher than the equilibrium profits in the one-shot game. This demonstrates that the efficiency of the supply chain is improved in the repeated game under certain conditions, which is different from the common conclusion that the equilibrium profit in the one-shot game is the first-best outcome (e.g., [20]).

In addition, we find that, in such a coopetition supply chain, when there is a relatively small adjustment speed difference, the performance of the coopetition supply chain is improved. This result is consistent with the bifurcation diagrams as shown in Figures 5 and 6, where the system comes into a two-periodic cycle from a chaotic state and thus becomes less complex.

\section{Conclusion}

Considering a coopetition supply chain consisting of an upstream ODM and a downstream OEM, we study a dynamic Cournot game in discrete time under bounded rationality. This paper extends the research on duopoly Cournot game with adjustment process by examining "competitive and cooperative interaction" combined with the Gradient Rule.

We find that the flip bifurcations of Cournot competition in this paper are consistent with previous studies (e.g., $[18,28,33,50])$. However, in this paper, the interaction between the OEM and the ODM either maintains the stability of the dynamic system or presents a destabilizing effect through a flip bifurcation. We show that such a bifurcation differs from the common bifurcation detected in the work of Cavalli and Naimzada [31]. Specifically, the dynamic system diverges and such a bifurcation would not lead to complex behavior: The dynamic system changes from a chaotic state to a two-periodic cycle, reducing the complexity of the dynamic game system. This paper is the first to investigate the dynamic analysis for Cournot game in a coopetition supply chain and renders the following findings: (i) A higher product substitutability has a positive impact on the system stability. (ii) As adjustment speeds increase from a smaller initial value, the Nash equilibrium becomes unstable. However, our results show that the complex behavior of the dynamic system is alleviated from chaos to a two-periodic cycle along with the OEM's adjustment speed greatly increasing. (iii) By comparing the influences of the adjustment speeds on the firms' average profits in the dynamic system 
with those in the one-shot game, we find that the dynamic adjustment strategy is beneficial to the coopetition supply chain and both players when the difference between the two firms' adjustment speeds is relatively small.

\section{Data Availability}

The data used to support the findings of this study are included within the article.

\section{Conflicts of Interest}

The authors declare that they have no conflicts of interest regarding the publication of this paper.

\section{Acknowledgments}

This work was supported by the National Natural Science Foundation of China (Grant no. 71971152).

\section{References}

[1] G. Linden, K. L. Kraemer, and J. Dedrick, "Who captures value in a global innovation system? The Case of Apple's iPod," in Proceedings of the Personal Computing Industry Center (PCIC) Working Paper, University of California, Irvine, CA, USA, June 2007.

[2] P. Gupta, M. Kim, and D. Levine, Insight: Apple and Samsung, Frenemies for Life, Reuters, London, UK, 2013.

[3] A. Ha, X. Long, and J. Nasiry, "Quality in supply chain encroachment," Manufacturing and Service Operations Management, vol. 18, no. 2, pp. 280-298, 2015.

[4] B. J. Nalebuff and A. M. Brandenburger, "Co-opetition: competitive and cooperative business strategies for the digital economy," Strategy \& Leadership, vol. 25, no. 6, pp. 28-33, 1997.

[5] Y. Wang, B. Niu, and P. Guo, "On the advantage of quantity leadership when outsourcing production to a competitive contract manufacturer," Production and Operations Management, vol. 22, no. 1, pp. 104-119, 2013.

[6] B. Bligiardi, A. I. Dormio, and F. Galati, "Successful coopetition strategy: evidence from Italian consortium," International Journal of Business, Management and Social Sciences, vol. 2, no. 4, pp. 1-8, 2011.

[7] H. Chen, Y. Yan, N. Ma et al., "Coopetition strategy and pricing timing in an outsourcing supply chain with uncertain operation risks," IEEE Transactions on Fuzzy Systems, vol. 27, no. 5, pp. 979-993, 2018.

[8] A. M. Brandenburger and B. J. Nalebuff, Co-opetition, Doubleday Currency, New York, NY, USA, 1996.

[9] H. Gurnani, M. Erkoc, and Y. Luo, "Impact of product pricing and timing of investment decisions on supply chain coopetition," European Journal of Operational Research, vol. 180, no. 1, pp. 228-248, 2007.

[10] A. Arya and B. Mittendorf, "The changing face of distribution channels: partial forward integration and strategic investments," Production and Operations Management, vol. 22, no. 5, pp. 1077-1088, 2013.

[11] M. Bengtsson and T. Raza-Ullah, "A systematic review of research on coopetition: toward a multilevel understanding," Industrial Marketing Management, vol. 57, pp. 23-39, 2016.

[12] C. Devece, D. E. Ribeiro-Soriano, and D. Palacios-Marqués, "Coopetition as the new trend in inter-firm alliances: literature review and research patterns," Review of Managerial Science, vol. 13, no. 2, pp. 207-226, 2019.

[13] B. Niu, Y. Wang, and P. Guo, "Equilibrium pricing sequence in a co-opetitive supply chain with the ODM as a downstream rival of its OEM," Omega, vol. 57, no. 57, pp. 249-270, 2015.

[14] M. Bengtsson and M. Johansson, "Managing coopetition to create opportunities for small firms," International Small Business Journal: Researching Entrepreneurship, vol. 32, no. 4, pp. 401-427, 2014.

[15] Y. Wang and X. Sun, "Dynamic vs. Static wholesale pricing strategies in a dual-channel green supply chain," Complexity, vol. 2019, Article ID 8497070, 14 pages, 2019.

[16] M. Bengtsson, S. Kock, E.-L. Lundgren-Henriksson, and M. H. Näsholm, "Coopetition research in theory and practice: growing new theoretical, empirical, and methodological domains," Industrial Marketing Management, vol. 57, pp. 4-11, 2016.

[17] Y. Yang, J. Ma, and H. Tu, "Chaotic characteristics and application of cooperative game and evolutionary game," Discrete Dynamics in Nature and Society, vol. 2014, Article ID 908093, 13 pages, 2014.

[18] S. S. Askar, "Complex dynamic properties of Cournot duopoly games with convex and log-concave demand function," Operations Research Letters, vol. 42, no. 1, pp. 85-90, 2014.

[19] L. Shi, Z. Sheng, and F. Xu, "The dynamics of competition in remanufacturing: a stability analysis," Economic Modelling, vol. 50, pp. 245-253, 2015.

[20] J. Ma and L. Xie, "The comparison and complex analysis on dual-channel supply chain under different channel power structures and uncertain demand," Nonlinear Dynamics, vol. 83, no. 3, pp. 1379-1393, 2016.

[21] M. J. Villena and A. A. Araneda, "Dynamics and stability in retail competition," Mathematics and Computers in Simulation, vol. 134, pp. 37-53, 2017.

[22] X. Yuan and H. B. Hwarng, "Stability and chaos in demandbased pricing under social interactions," European Journal of Operational Research, vol. 253, no. 2, pp. 472-488, 2016.

[23] S. S. Askar and M. F. Elettreby, "The impact of cost uncertainty on Cournot oligopoly games," Applied Mathematics and Computation, vol. 312, pp. 169-176, 2017.

[24] Y. Peng, Q. Lu, and Y. Xiao, "Complex dynamics analysis for a remanufacturing duopoly model with nonlinear cost," Physica A: Statistical Mechanics and Its Applications, vol. 514, pp. 658-670, 2019.

[25] F. Wu and C. Wang, "Dynamic pricing strategy and coordination in a dual-channel supply chain considering service value," Applied Mathematical Modelling, vol. 54, pp. 722-742, 2018.

[26] Z. Guo, "Complexity and implications on channel conflict under the uncertain impacts of online customer reviews," Nonlinear Dynamics, vol. 96, no. 3, pp. 1971-1987, 2019.

[27] G. I. Bischi, U. Merlone, and E. Pruscini, "Evolutionary dynamics in club goods binary games," Journal of Economic Dynamics and Control, vol. 91, pp. 104-119, 2018.

[28] J. Zhou, W. Zhou, T. Chu, Y.-x. Chang, and M.-j. Huang, "Bifurcation, intermittent chaos and multi-stability in a twostage cournot game with R\&D spillover and product differentiation," Applied Mathematics and Computation, vol. 341, pp. 358-378, 2019.

[29] W. Chang and X. X. Wang, "On the stability and multistability in a duopoly game with $R \& D$ spillover and price competition," Discrete Dynamics in Nature and Society, vol. 2019, Article ID 2369898, 20 pages, 2019.

[30] H. N. Agiza, A. S. Hegazi, and A. A. Elsadany, "Complex dynamics and synchronization of a duopoly game with 
bounded rationality," Mathematics and Computers in Simulation, vol. 58, no. 2, pp. 133-146, 2002.

[31] F. Cavalli and A. Naimzada, "A Cournot duopoly game with heterogeneous players: nonlinear dynamics of the gradient rule versus local monopolistic approach," Applied Mathematics and Computation, vol. 249, pp. 382-388, 2014.

[32] D. Léonard and K. Nishimura, "Nonlinear dynamics in the Cournot model without full information," Annals of Operations Research, vol. 89, pp. 165-173, 1999.

[33] H. N. Agiza and A. A. Elsadany, "Nonlinear dynamics in the Cournot duopoly game with heterogeneous players," Physica A: Statistical Mechanics and Its Applications, vol. 320, pp. 512-524, 2003.

[34] Z. Ding, X. Zhu, and S. Jiang, "Dynamical Cournot game with bounded rationality and time delay for marginal profit," Mathematics and Computers in Simulation, vol. 100, pp. 1-12, 2014.

[35] A. Agliari, A. K. Naimzada, and N. Pecora, "Nonlinear dynamics of a Cournot duopoly game with differentiated products," Applied Mathematics and Computation, vol. 281, pp. 1-15, 2016.

[36] A. A. Elsadany, "Dynamics of a cournot duopoly game with bounded rationality based on relative profit maximization," Applied Mathematics and Computation, vol. 294, pp. 253-263, 2017.

[37] G. P. Cachon and P. T. Harker, "Competition and outsourcing with scale economies," Management Science, vol. 48, no. 10, pp. 1314-1333, 2002.

[38] T. Xiao and X. Qi, "Price competition, cost and demand disruptions and coordination of a supply chain with one manufacturer and two competing retailers," Omega-the International Journal of Management Science, vol. 12, no. 36, pp. 741-753, 2008.

[39] N. Singh and X. Vives, "Price and quantity competition in a differentiated duopoly," RAND Journal Economics, vol. 15, no. 4, pp. 546-554, 2013.

[40] J. Schofield, "Quanta and compal will be world's biggest notebook makers in 2011. ZDNet UK," 2010, http://www. zdnet.com.

[41] H. L. Lee, V. Padmanabhan, and T. A. Taylor, "Price protection in the personal computer industry," Management Science, vol. 46, no. 4, pp. 467-482, 2000.

[42] M. Whang, "The price is right," Computer Reseller NewsDistributor Census Supplemen, vol. 14, pp. 117-118, 1994.

[43] Y. Aviv and A. Pazgal, "Optimal pricing of seasonal products in the presence of forward-looking consumers," Manufacturing \& Service Operations Management, vol. 10, no. 3, pp. 339-359, 2008.

[44] O. Besbes and I. Lobel, "Intertemporal price discrimination: structure and computation of optimal policies," Management Science, vol. 61, no. 1, pp. 92-110, 2015.

[45] G. P. Cachon and P. Feldman, "Price commitments with strategic consumers: why it can Be optimal to discount more frequently ... than optimal," Manufacturing \& Service Operations Management, vol. 17, no. 3, pp. 399-410, 2015.

[46] G. I. Bischi and A. Naimzada, "Global analysis of a dynamic duopoly game with bounded rationality," in Advances in Dynamic Games and Applications, pp. 361-385, Birkhäuser, Boston, MA, USA, 2000.

[47] A. K. Naimzada and L. Sbragia, "Oligopoly games with nonlinear demand and cost functions: two boundedly rational adjustment processes," Chaos, Solitons \& Fractals, vol. 29, no. 3, pp. 707-722, 2006.
[48] R. L. Devaney, An Introduction to Chaotic Dynamical Systems, Benjamin-Cummings, San Francisco, CA, USA, 2nd edition, 1989.

[49] H. W. Lorenz, Nonlinear Dynamical Economics and Chaotic Motion, Springer-Verlag, Berlin, Germany, 1989.

[50] S. S. Askar and K. Alnowibet, "Nonlinear oligopolistic game with isoelastic demand function: rationality and local monopolistic approximation," Chaos, Solitons \& Fractals, vol. 84, pp. 15-22, 2016.

[51] A. Agliari, G.-I. Bischi, and R. Dieci, "Global bifurcations of closed invariant curves in two-dimensional maps: a computer assisted study," International Journal of Bifurcation and Chaos, vol. 15, no. 4, pp. 1285-1328, 2005. 